\title{
Comparison of Two Numerical Schemes of the Fractional Chemical Model
}

Khaled Mohammed SAAD ${ }^{1}$ and Khaled M Saad ${ }^{2,3}$

${ }^{1}$ Affiliation not available

${ }^{2}$ Department of Mathematics, College of Arts and Sciences, Kingdom of Saudi Arabia, Najran University

${ }^{3}$ Department of Mathematics, Faculty of Applied Science, Taiz University

June 21, 2021

\section{Hosted file}

Khaled2021.pdf available at https://authorea.com/users/377697/articles/527015-comparison-oftwo-numerical-schemes-of-the-fractional-chemical-model 